\title{
Age Changes in Dentin and Dental Pulp: A Radiographic Study
}

\author{
Shashank Gupta ${ }^{1}$, Garima Gupta², Neha Gupta ${ }^{3}$
}

\begin{abstract}
Introduction: We are all biologically unique and become more diverse as we age, enhancing the spice of life with increasing variety. In many ways, the teeth are unique organs of the body; they are the most durable part of the skeleton. The gradual changes taking place in the dental tissue after the teeth are fully formed are of clinical importance and need to be recognized by the dental surgeon as being a normal finding and not a part of the disease process.

Aims and Objectives: The aim of this study is to estimate relationship between size of the pulp and the dentin with age and to know if there is a significant difference in size of the pulp and the dentin among various age groups. The clinical significance of the study will be to use the average tooth length and width obtained by this study as the standard guideline for age estimation and to utilize the results of the present study in forensic science and anthropology and as an aging biomarker.

Results: From the study, it was concluded that in both males and females there is decrease in root canal length and width with increasing age, which is attributed to secondary dentin formation. In the age group of 11-60, the length and width of pulp canals of mandibular central and lateral incisors decreased with the advancing age and this difference is statistically significant with the $p$ value of less than 0.000 .

Conclusion: In the future computer-assisted measurements, i.e., latest digital radiographic techniques are suggested to measure the above parameters; this may could throw light on forensic applications, medicolegal issues, and legal issues regarding age estimation by measuring root canal length and width.

Keywords: Age estimation, Pulp chamber width, Root canal width, Secondary dentin.

Journal of Mahatma Gandhi University of Medical Sciences \& Technology (2018): 10.5005/jp-journals-10057-0084
\end{abstract}

\section{INTRODUCTION}

We are all biologically unique and become more diverse as we age, enhancing the spice of life with increasing variety. ${ }^{1}$ In many ways, the teeth are unique organs of the body; they are the most durable part of the skeleton. ${ }^{2}$ The gradual changes taking place in the dental tissue after the teeth are fully formed are of clinical importance and need to be recognized by the dental surgeon as being a normal finding and not a part of the disease process. ${ }^{3}$ Teeth are the hardest bodily structures. Fully formed teeth show aging changes that mirror those seen systemically. Teeth can be used to give the age range for forensic science and anthropology.

\section{Aims and Овjectives}

\section{Aims}

- To estimate relationship between size of the pulp and the dentin with age.

- To know if there is a significant difference in size of the pulp and the dentin among various age groups.

\section{Objectives}

- To use the average tooth length and width obtained by this study as the standard guideline for age estimation.

- To utilize the results of the present study in forensic science and anthropology and as an aging biomarker.

\section{Materials and Methods Source of Data}

A study was carried out in Department of Oral Medicine and Radiology, NIMS Dental College, Jaipur, to estimate relationship between size of the pulp and the dentin with age.
${ }^{1}$ Department of Medicine and Radiology, Mahatma Gandhi Dental College and Hospital, Mahatma Gandhi University of Medical Sciences and Technology, Jaipur, Rajasthan, India

${ }^{2}$ Department of Orthodontics and Dentofacial Orthopedics, Gupta Dental and Implant Centre, Jaipur, Rajasthan, India

${ }^{3}$ Department of Pathology, SMS Medical College, Jaipur, Rajasthan, India

Corresponding Author: Garima Gupta, Department of Orthodontics and Dentofacial Orthopedics, Gupta Dental and Implant Centre, Jaipur, Rajasthan, India, Phone: +91 9837743707, e-mail: 1garima6@ gmail.com

How to cite this article: Gupta S, Gupta G, Gupta N. Age Changes in Dentin and Dental Pulp: A Radiographic Study. J Mahatma Gandhi Univ Med Sci Tech 2018;3(3):82-87.

Source of support: Nil

Conflict of interest: None

\section{Method of Collecting the Data \\ Inclusion Criteria}

The study group comprised 200 apparently healthy subjects in the age group of 11-60 years of both sex, drawn from those attending the OPD of the Oral Medicine and Radiology Department/rural dental camps, which satisfied the inclusion criteria with patients written consent.

\section{Exclusion Criteria}

- Mandibular incisors with any caries, attrition, abrasion, erosion, fracture, and restoration

- Patients having any systemic disease that can cause calcification of the root canal

(-) The Author(s). 2018 Open Access This article is distributed under the terms of the Creative Commons Attribution 4.0 International License (https://creativecommons. org/licenses/by-nc/4.0/), which permits unrestricted use, distribution, and non-commercial reproduction in any medium, provided you give appropriate credit to the original author(s) and the source, provide a link to the Creative Commons license, and indicate if changes were made. The Creative Commons Public Domain Dedication waiver (http://creativecommons.org/publicdomain/zero/1.0/) applies to the data made available in this article, unless otherwise stated. 
- Patients who have undergone/undergoing corticosteroid therapy

- If the radiographs of $31,32,41$, and 42 show more than one root canal, then those radiographs will not be included in the study

- Patient with severe periodontal disease

\section{Methodology}

A total of 200 normal subjects are divided into six age groups with equal sex distribution in the age range of $11-60$ years.

\section{Examination of the Subjects}

- The subjects were made to sit comfortably on the physiological dental chair with artificial illumination. Then, diluted $0.2 \%$ chlorhexidine gluconate mouth wash was given to rinse the oral cavity.

- Wearing sterile hand gloves and mouth mask, the subjects were examined under artificial illumination. The clinical examination was carried out by adopting the methods of Kerr, Ash, and Millard (1983), and relevant data were recorded.

\section{Statistical Analysis}

Formulae used for analysis:

$$
\begin{aligned}
\text { Mean, } x & =\frac{\sum x_{i}}{N} i=1,2, \& n \\
\text { Standard Deviation, SD } & =\sqrt{\frac{\sum\left(x_{i}-\bar{x}\right)^{2}}{n-1}} \\
\text { Variance } & =S D^{2} \\
\text { Standard Error, } S E & =S D \sqrt{n}
\end{aligned}
$$

\section{Multiple Group Comparison (Age Groups)}

Analysis of variance-one-way classification Snedecor's $F$ test

\section{Variance ratio $F=$}

(Between group variation) / (Within group variation)

\section{Results}

- Patients from NIMS Dental College and Hospital were selected and divided into five age groups, i.e., 11-20 years, 21-30 years, $31-40$ years, $41-50$ years, and $51-60$ years.

- Each age group comprised of 40 subjects including 20 males and 20 females (Table 1 and Fig. 1), and intraoral periapical (IOPA) radiographs of mandibular anterior teeth were made using the paralleling technique and interpretation was made with the help of the Nikon profile projector.

- Radiographic observations of 200 subjects were compiled and results were statistically analyzed (Figs 2 to 9).

- With the increasing age, there is root canal width in mandibular lateral incisors in both males and females among the different age groups, which was statistically high significant difference $(p<0.000)$ (Tables 2 to 9$)$.

\section{Discussion}

- The present study is conducted to estimate the relationship between the size of the pulp and the dentin with age, among
Table 1: Distribution of age groups and sex

\begin{tabular}{llccc}
\hline Groups & $\begin{array}{l}\text { Age } \\
\text { (in years) }\end{array}$ & Male & Female & Total \\
\hline Group I & $11-20$ & 20 & 20 & 40 \\
Group II & $21-30$ & 20 & 20 & 40 \\
Group III & $31-40$ & 20 & 20 & 40 \\
Group IV & $41-50$ & 20 & 20 & 40 \\
Group V & $51-60$ & 20 & 20 & 40 \\
Total & $11-60$ & 100 & 100 & 200 \\
\hline
\end{tabular}

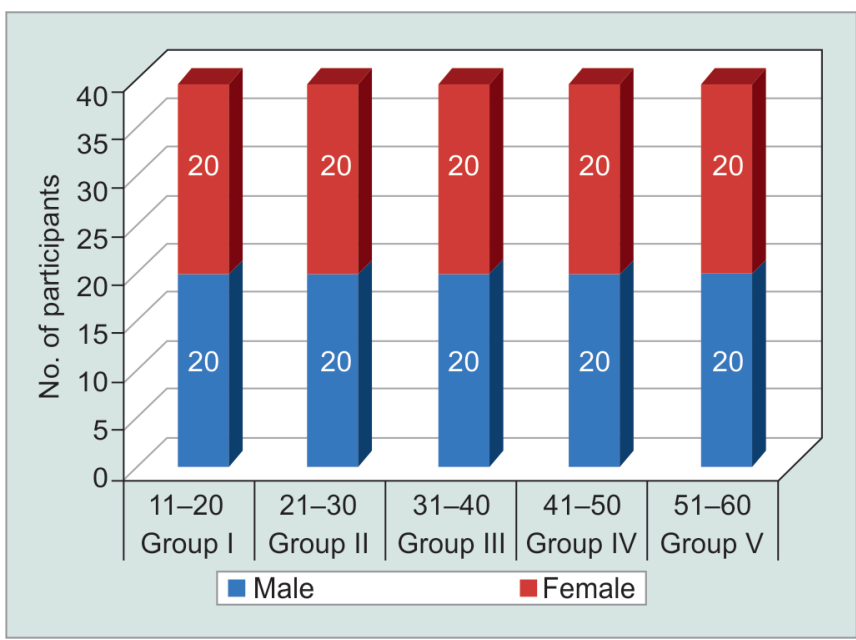

Fig. 1: No. of participants

various age groups (11-20 years, $21-30$ years, 31-40 years, $41-50$ years, 51-60 years) in males and females using root canal length and width of mandibular central and lateral incisors.

- The findings were found to be highly significant with $p<0.00$, suggesting decrease in total root canal length and width with advancing age. These findings are in the accordance to those of Morse ${ }^{4}$ in which the mean root canal length for the 17-29 years age group is $18.54 \mathrm{~mm}, 30-39$ is $17.40 \mathrm{~mm}, 40-49$ is $16.40 \mathrm{~mm}$, and $50-59$ is $14.43 \mathrm{~mm}$. There is corresponding decrease in root canal length with advancing age.

- The measurements indicated a definite decrease in root canal width both in males and females as age increased in increments of 10 years from 11 years to 59 years. These findings are in accordance with Morse in which root canal length decreased with the advancing age due to continued deposition of the secondary dentin.

- Siddiqui ${ }^{5}$ stated that dentin thickness and pulp space width show variation with age due to continued dentin deposition, which can be a factor affecting the success of treatment for different age groups as thickness of the dentin and width of the pulp space go on decreasing with age with $p<0.05$ which is statically significant, which is in the favor of present study with $p<0.00$ which is highly significant.

- Mjor, ${ }^{3}$ Lucy, Pollard ${ }^{6}$ and Kvaal et al. ${ }^{7}$ stated that secondary dentin deposition is a valuable age factor and measurements of root canal from mandibular central incisors have shown a significant difference between the 10 years age group and there is resultant obliteration of the pulp chamber as the age advances, which is in favor of our study where root canal width is decreasing with age. .,9 $^{8}$ 


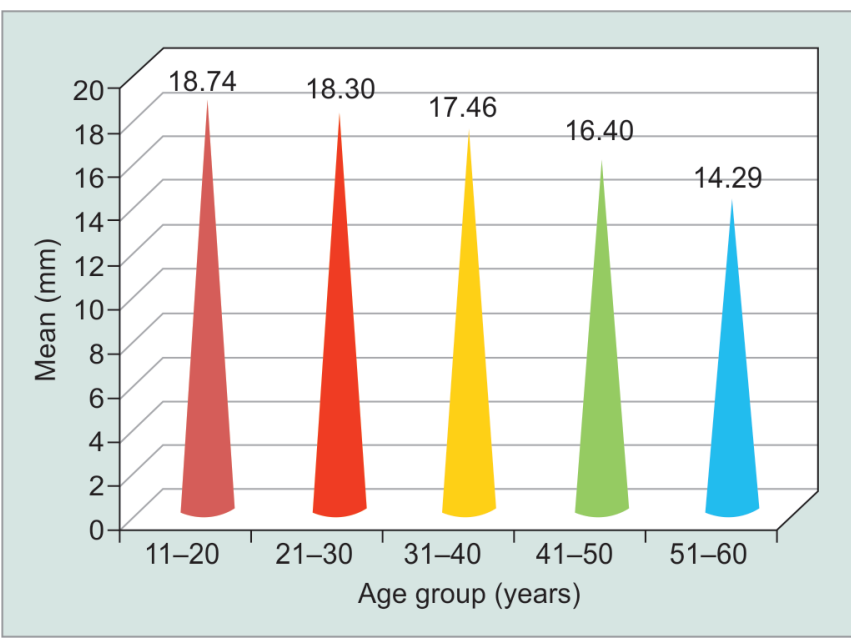

Fig. 2: Root canal length

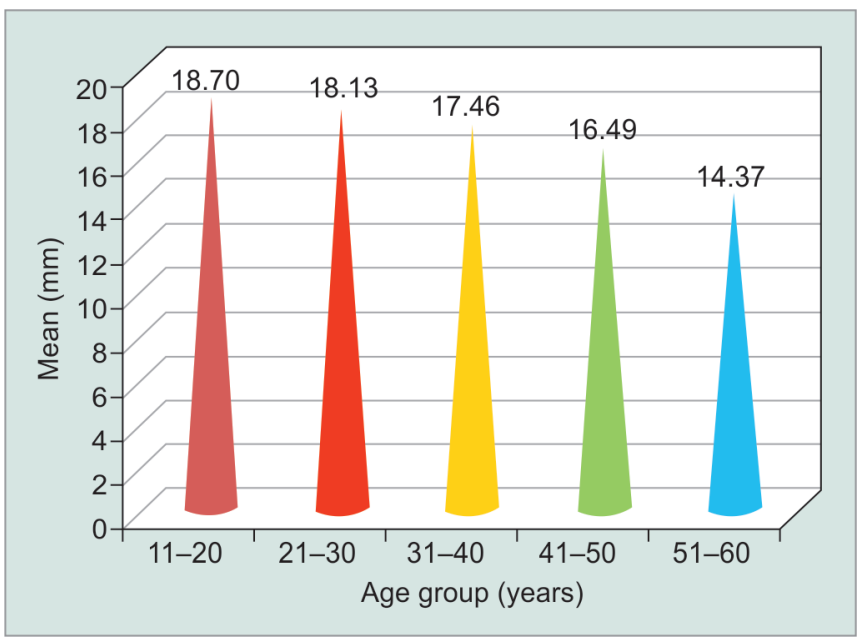

Fig. 4: Root canal length

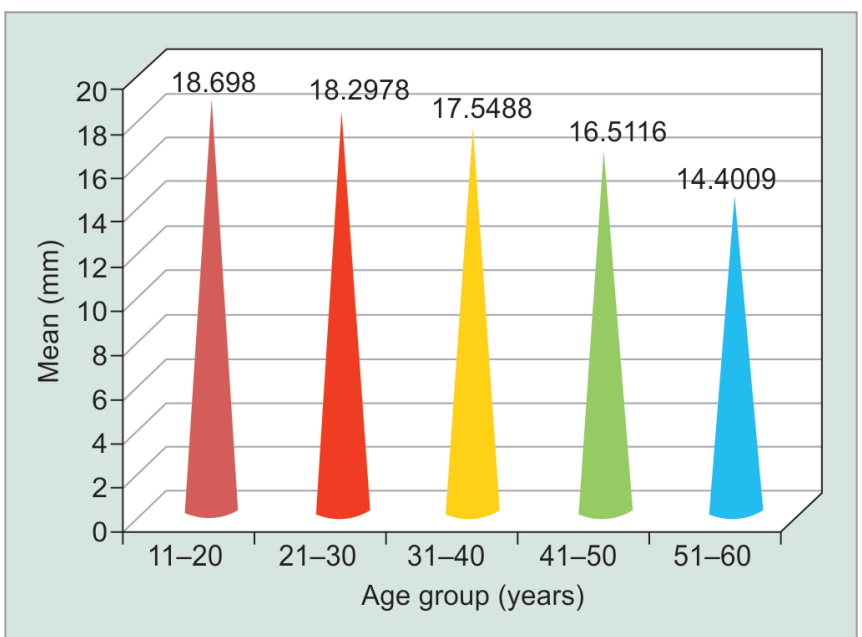

Fig. 6: Root canal length

\section{Conclusion}

From the study, it can be concluded that in both males and females:

- There is decrease in root canal length with increasing age.

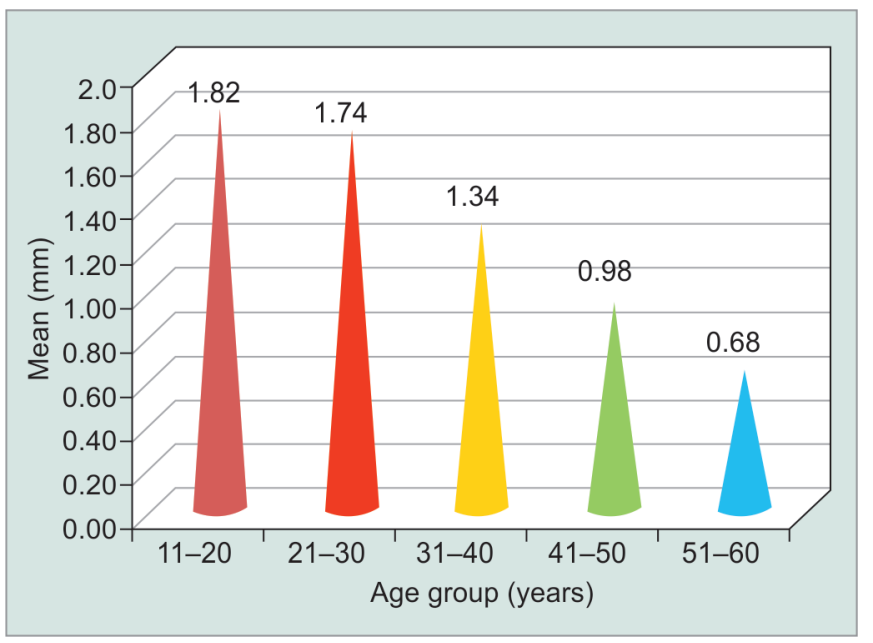

Fig. 3: Root canal width

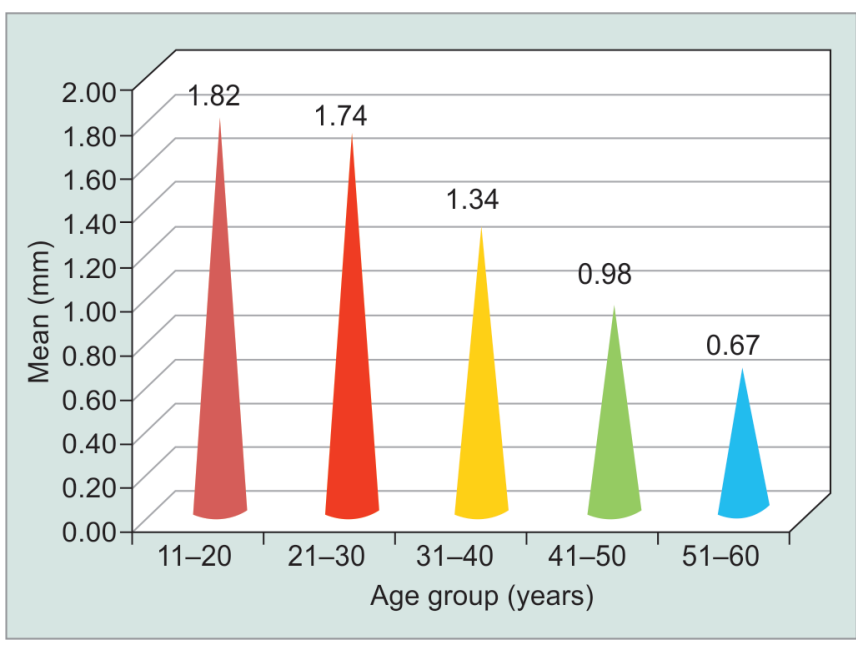

Fig. 5: Root canal width

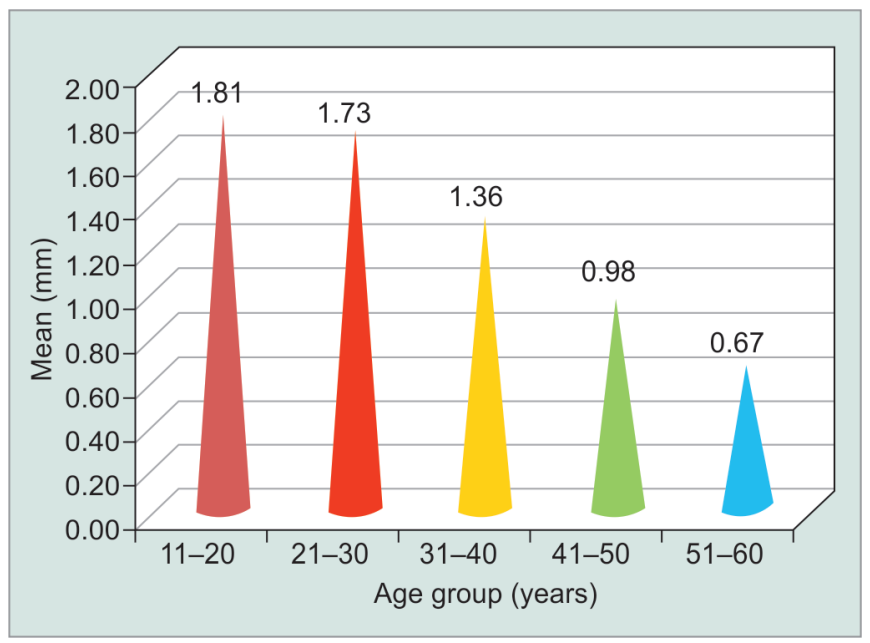

Fig. 7: Root canal width

- There is decrease in root canal width with increasing age, which is attributed due to secondary dentin formation.

- In the age group of 11-60 years, the length and width of pulp canals of mandibular central and lateral incisors decreased with 


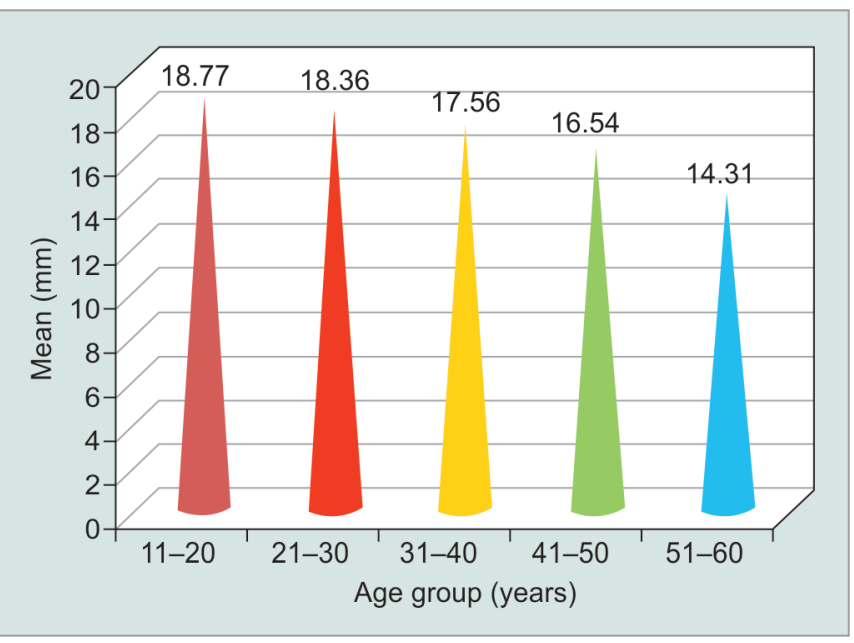

Fig. 8: Root canal length

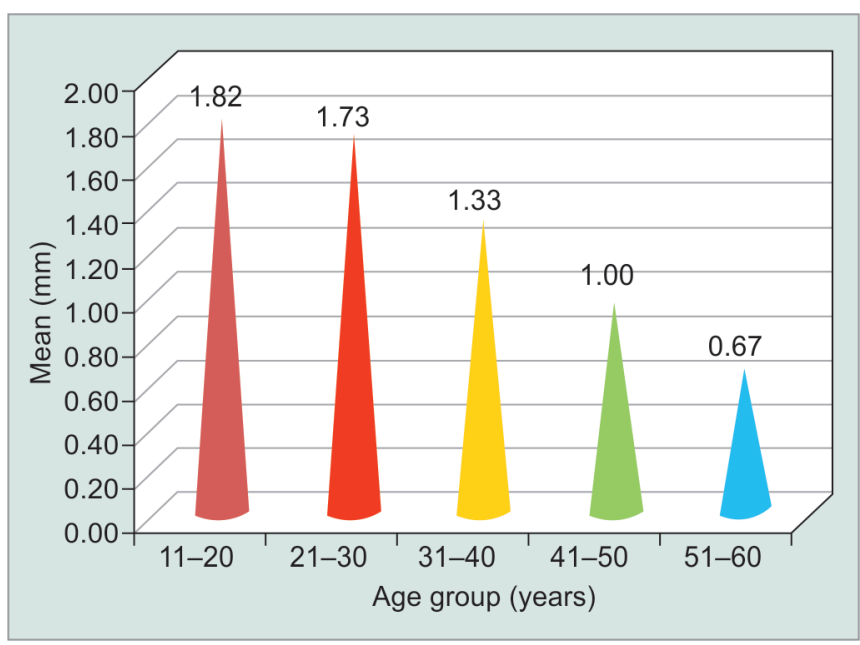

Fig. 9: Root canal width

Table 2: Root canal length in mandibular central incisors in males

\begin{tabular}{lllllll}
\hline Age group (years) & $n$ & Mean & Std. deviation & Std. error & Minimum & Maximum \\
\hline $11-20$ & 20 & 18.7490 & 0.34408 & 0.07694 & 18.13 & 19.30 \\
$21-30$ & 20 & 18.3005 & 0.19088 & 0.04268 & 18.05 & 18.75 \\
$31-40$ & 20 & 17.4688 & 0.27975 & 0.06256 & 17.01 & 18.93 \\
$41-50$ & 20 & 16.4163 & 0.37950 & 0.08486 & 13.67 & 17.01 \\
$51-60$ & 20 & 14.2975 & 0.30644 & 0.06852 & 13.70 \\
Total & 100 & 17.0464 & 1.62375 & 0.16238 & 13.67 & 19.30 \\
\hline
\end{tabular}

$F=668.960, p=0.000$ (highly significant)

Table 3: Root canal width in mandibular central incisors in males

\begin{tabular}{lllllll}
\hline Age group (years) & $n$ & Mean & Std. deviation & Std. error & Minimum & Maximum \\
\hline $11-20$ & 20 & 1.8177 & 0.09287 & 0.02077 & 1.73 & 1.03 \\
$21-30$ & 20 & 1.7371 & 0.01859 & 0.00416 & 1.70 & 1.27 \\
$31-40$ & 20 & 1.3410 & 0.04241 & 0.00948 & 0.64 & 1.42 \\
$41-50$ & 20 & 0.9835 & 0.08261 & 0.01847 & 0.00282 & 0.66 \\
$51-60$ & 20 & 0.6756 & 0.01262 & 0.002 & 0.72 \\
Total & 100 & 1.3110 & 0.44199 & 0.04420 & 0.64 & 2.03 \\
\hline
\end{tabular}

$F=1338.057, p=0.000$ (highly significant)

Table 4: Root canal length in mandibular central incisors in females

\begin{tabular}{lllllll}
\hline Age group (years) & $n$ & Mean & Std. deviation & Std. error & Minimum & Maximum \\
\hline $11-20$ & 20 & 18.7030 & 0.26941 & 0.06024 & 18.13 & 19.10 \\
$21-30$ & 20 & 18.1278 & 0.28031 & 0.06268 & 17.60 & 18.60 \\
$31-40$ & 20 & 17.4625 & 0.34973 & 0.07820 & 16.70 & 18.05 \\
$41-50$ & 20 & 16.4878 & 0.13849 & 0.03097 & 16.10 & 16.70 \\
$51-60$ & 20 & 14.3703 & 0.24375 & 0.05450 & 13.85 & 14.85 \\
Total & 100 & 17.0303 & 1.55009 & 0.15501 & 13.85 & 19.10 \\
\hline
\end{tabular}

$F=820.833, p=0.000$ (highly significant)

the advancing age and this difference is statistically significant with $p$ value $<0.000$. Thus, this noninvasive, nondestructive, and easily accessible method can be employed to assess the age changes.
- Use of areas of the tooth for estimation of age is promising as also has been suggested by others. Further, in the future computerassisted measurements, i.e., the latest digital radiographic technique, are suggested to measure the above parameters; 
Age Changes in Dentin and Dental Pulp: A Radiographic Study

Table 5: Root canal width in mandibular central incisors in females

\begin{tabular}{lllllll}
\hline Age group (years) & $n$ & Mean & Std. deviation & Std. error & Minimum & Maximum \\
\hline $11-20$ & 20 & 1.8091 & 0.11475 & 0.02566 & 1.56 & 2.00 \\
$21-30$ & 20 & 1.7380 & 0.01831 & 0.00409 & 1.70 & 1.79 \\
$31-40$ & 20 & 1.3310 & 0.04745 & 0.01061 & 1.25 & 1.41 \\
$41-50$ & 20 & 0.9808 & 0.02935 & 0.00656 & 0.94 & 1.05 \\
$51-60$ & 20 & 0.6661 & 0.01058 & 0.00237 & 0.65 & 0.68 \\
Total & 100 & 1.3050 & 0.44302 & 0.04430 & 0.65 & 2.00 \\
\hline
\end{tabular}

$F=1428.141, p=0.000$ (highly significant)

Table 6: Root canal length in mandibular lateral incisors in males

\begin{tabular}{lllllll}
\hline Age group (years) & $n$ & Mean & Std. deviation & Std. error & Minimum & Maximum \\
\hline $11-20$ & 20 & 18.6980 & 0.29243 & 0.04624 & 18.26 & 17.55 \\
$21-30$ & 20 & 18.2978 & 0.22702 & 0.03590 & 17.52 & 17.17 \\
$31-40$ & 20 & 17.5488 & 0.19062 & 0.03014 & 15.97 & 13.55 \\
$41-50$ & 20 & 16.5116 & 0.22766 & 0.03600 & 0.04497 & 13 \\
$51-60$ & 20 & 14.4009 & 0.28441 & 0.11036 & 13.55 \\
Total & 100 & 17.0914 & 1.56077 & & 14.85 \\
\hline
\end{tabular}

$F=2824.343, p=0.000$ (highly significant)

Table 7: Root canal width in mandibular lateral incisors in males

\begin{tabular}{lllllll}
\hline Age group (years) & $n$ & Mean & Std. deviation & Std. error & Minimum & Maximum \\
\hline $11-20$ & 20 & 1.8058 & 0.08373 & 0.01872 & 1.74 & 1.61 \\
$21-30$ & 20 & 1.7330 & 0.03898 & 0.00872 & 1.02 & 1.78 \\
$31-40$ & 20 & 1.3583 & 0.04635 & 0.01036 & 0.00656 & 1.43 \\
$41-50$ & 20 & 0.9808 & 0.02935 & 0.00197 & 0.65 & 0.05 \\
$51-60$ & 20 & 0.6692 & 0.00880 & 0.04397 & 0.65 & 2.02 \\
Total & 100 & 1.3094 & 0.43973 & & \\
\hline
\end{tabular}

$F=2035.964, p=0.000$ (highly significant)

Table 8: Root canal length in mandibular lateral incisors in females

\begin{tabular}{lclcccc}
\hline Age group (years) & $n$ & Mean & Std. deviation & Std. error & Minimum & Maximum \\
\hline $11-20$ & 20 & 18.7660 & 0.32651 & 0.07301 & 18.32 & 19.55 \\
$21-30$ & 20 & 18.3605 & 0.21508 & 0.04809 & 17.95 & 17.33 \\
$31-40$ & 20 & 17.5558 & 0.13008 & 0.02909 & 15.81 & 17.83 \\
$41-50$ & 20 & 16.5355 & 0.29327 & 0.06558 & 13.57 & 17.13 \\
$51-60$ & 20 & 14.3068 & 0.31755 & 0.07101 & 17.85 \\
Total & 100 & 17.1049 & 16.7830 & 17.4268 & 13.55 \\
\hline
\end{tabular}

$F=889.784, p=0.000$ (highly significant)

Table 9: Root canal width in mandibular lateral incisors in females

\begin{tabular}{lllllll}
\hline Age group (years) & $n$ & Mean & Std. deviation & Std. error & Minimum & Maximum \\
\hline $11-20$ & 40 & 1.8245 & 0.08984 & 0.01421 & 1.74 & 1.02 \\
$21-30$ & 40 & 1.7329 & 0.03090 & 0.00489 & 0.00761 & 1.24 \\
$31-40$ & 40 & 1.3339 & 0.04810 & 0.00601 & 0.94 & 1.48 \\
$41-50$ & 40 & 0.9958 & 0.03800 & 0.00113 & 0.65 & 1.11 \\
$51-60$ & 40 & 0.6700 & 0.00712 & 0.03114 & 0.65 & 0.68 \\
Total & 200 & 1.3114 & 0.44040 & 2.02 \\
\hline
\end{tabular}

$F=3710.212, p=0.000$ (highly significant) 
this may could throw light on forensic applications, medicolegal issues, and legal issues regarding age estimation by measuring root canal length and width.

\section{References}

1. Adams D. Age changes in oral structures. Dent Update 1991;18(1): 15-17.

2. Cameron JM, Smith BG. The tooth and age determination. In: Forensic Dentistry. Edinburgh: Churchill Livingstone; 1974. pp. 23-45.

3. Mjor IA. Age changes in the teeth. In: Pedersen Poul-Hohm, HeradILoe. Geriatric Dentistry, 1st ed., Munksgaard, Copenhegan; 1986. pp. 94-100.

4. Morse DR, Esposito JV, Schoor RS. A radiographic study of aging changes of the dental pulp and dentin in normal teeth. Quintessence Int 1993;24(5):329-333.
5. Siddiqui FA, Sheikh A, Akhtar SA, et al. Radiographic Evaluation of dentin thickness and pulp space width for different age groups. JPDA 2012;21(2):99-102.

6. Lucy D, Pollard AM. Further comments on the estimation of error associated with the Gustafson dental age estimation method. J Forensic Sci 1995;40(2):222-227. DOI: 10.1520/JFS15346J.

7. Kvaal IS, Kolltveit KM, Thomsen IO, et al. Age estimation of adults from dental radiographs. Forensic Sci Int 1995;74(3):175-185. DOI: 10.1016/0379-0738(95)01760-G.

8. Nitzan DW, Michaeli $Y$, Weinreb N, et al. The effect of aging on tooth morphology: a study on impacted teeth. Oral Surg Oral Med Oral Pathol 1986;61(1):54-60. DOI: 10.1016/0030-4220(86)90203-3.

9. Murray PE, Stanley HR, Matthews JB, et al. Age-related odontometric changes of human teeth. Oral Surg Oral Med Oral Pathol Oral Radiol Endod 2002;93(4):474-482. DOI: 10.1067/moe.2002. 120974. 